\title{
Time-Dependent Reversal of Long-Term Potentiation by Low-Frequency Stimulation at the Hippocampal Mossy Fiber-CA3 Synapses
}

\author{
Yea-Lin Chen, Chiung-Chun Huang, and Kuei-Sen Hsu \\ Department of Pharmacology, College of Medicine, National Cheng-Kung University, Tainan City 701, Taiwan
}

\begin{abstract}
Using mouse hippocampal slices, we studied the induction of depotentiation of long-term potentiation (LTP) at the mossy fiber synapses onto CA3 pyramidal neurons. A long train of low-frequency (1 Hz/900 pulses) stimulation (LFS) induced a long-term depression of baseline synaptic transmission or depotentiation of previously established LTP, which was reversible and was independent of NMDA receptor activation. This LFSinduced depotentiation was observed when the stimulus was delivered 1 or 10 min after LTP induction. However, when LFS was applied at 30 min after induction, significantly less depotentiation was found. The induction of depotentiation on one input was associated with a heterosynaptic reverse of the LTP induced previously on a separate pathway. In addition, this LFS-induced depotentiation appeared to be mediated by the activation of group 2 metabotropic glutamate receptors (mGluRs), because it was mimicked by the bath-applied group 2 agonist $\left(2 S, 2^{\prime} R, 3^{\prime} R\right)-2-\left(2^{\prime}, 3^{\prime}\right.$-dicarboxycyclopropyl) glycine
\end{abstract}

and was specifically inhibited by the group 2 antagonists $(S)$ $\alpha$-methyl-4-carboxyphenylglycine and $(\alpha S)$ - $\alpha$-amino- $\alpha$-(1S,2S)2-carboxycyclopropyl-9H-xanthine-9-propanic acid. Moreover, the induction of depotentiation was entirely normal when synaptic transmission is blocked by glutamate receptor antagonist kynurenic acid and was associated with a reversal of pairedpulse facilitation attenuation during LTP expression. Pretreatment of the hippocampal slices with $\mathrm{G}_{\mathrm{i} / \mathrm{o}}$-protein inhibitor pertussis toxin (PTX) prevented the LFS-induced depotentiation. These results suggest that the activation of presynaptic group 2 mGluRs and in turn triggering a PTX-sensitive $\mathrm{G}_{\mathrm{i} / \mathrm{o}}$-proteincoupled signaling cascade may contribute to the LFS-induced depotentiation at the mossy fiber-CA3 synapses.

Key words: long-term potentiation (LTP); long-term depression (LTD); depotentiation; metabotropic glutamate receptor (mGluR); mossy fiber pathway; hippocampus
Long-term potentiation (LTP), a persistent increase in the efficacy of synaptic transmission induced by brief high-frequency stimulation of afferent pathways, has been considered to be an important component of the cellular basis of learning and memory in the brain (Bliss and Collingridge, 1993). However, the very persistence of LTP is itself problematical, because it could lead to a saturation of all modifiable synapses in a potentiated state, making them impossible to store additional new information. Thus, theoretical work has proposed that, in addition to a process such as LTP, there must also be existing mechanisms for counteracting enduring synaptic potentiation (Sejnowksi, 1977; Bienenstock et al., 1982; Wilshaw and Dayan, 1990). Until relatively recently, the idea of a depressive counterpart to LTP has become increasingly apparent, partly because considerable experimental evidence has been obtained that LTP can be reversed by various manipulations when administered within several minutes after LTP induction. For example, it has been shown that a brief period of hypoxia or application of adenosine receptor agonists reverses LTP in the CA1 region of hippocampal slices if applied within 1-3 min after LTP induction but not at time thereafter (Arai et al., 1990a,b). This time-dependent reversal of LTP was

Received Nov. 27, 2000; revised March 5, 2001; accepted March 13, 2001.

This work was supported by Academic Excellence Program of the Ministry of Education Grant 89-B-FA08-1-4 and National Health Research Institute Grant NHRI-GT-EX89S837C of Taiwan, Republic of China.

Correspondence should be addressed to Dr. Kuei-Sen Hsu, Department of Pharmacology, College of Medicine, National Cheng-Kung University, 1 Ta-Hsiue Road, Tainan City 701, Taiwan. E-mail: richard@mail.ncku.edu.tw.

Copyright (C) 2001 Society for Neuroscience 0270-6474/01/213705-10\$15.00/0 also effectively induced by afferent low-frequency stimulation (LFS) (1-5 Hz) delivered within 10 min after LTP induction, both in vivo (Barrionuevo et al., 1980; Stäubli and Lynch, 1990) and in vitro (Fujii et al., 1991; Bashir and Collingridge, 1992; O'Dell and Kandel, 1994; Huang et al., 1999). The reversal of synaptic strength from the potentiated state to pre-LTP levels has been termed "depotentiation" and may provide a mechanism of preventing the saturation of the synaptic potentiation and increase the efficiency and the capacity of the information storage of the neuronal networks.

In the time since the depotentiation discovery, most work on the mechanisms of this phenomenon in the mammalian brain has focused on the form of Hebbian forms of LTP, such as Schaffer collateral-CA1 LTP and perforant path-dentate gyrus LTP (Huang and Hsu, 2001). The question now arises, can nonHebbian forms of LTP also show depotentiation? One of the extensive study examples of non-Hebbian forms of LTP was elicited by a high-frequency tetanic stimulation (TS) of the synapses made by mossy fibers onto CA3 pyramidal neurons in the hippocampus (Harris and Cotman, 1986; Zalutsky and Nicoll, 1990). At these synapses, LTP induction seems to be independent of postsynaptic depolarization or $\mathrm{Ca}^{2+}$ influx through NMDA receptors; thus, it is thought to be triggered entirely within the presynaptic terminals (Zalutsky and Nicoll, 1990; Katsuki et al., 1991). In an attempt to make sense whether there is the existence of depotentiation in the non-Hebbian forms of LTP, we have therefore investigated the effect of depotentiating stimulation on the previously established LTP at the mossy fiber-CA3 synapses. Our data indicate that the reversal of LTP can be induced by LFS 
if the stimulus was delivered $<30$ min after LTP induction at these synapses and that the activation of group 2 metabotropic glutamate receptors (mGluRs) is necessary for its induction.

\section{MATERIALS AND METHODS}

Hippocampal slice preparation. Animal care and handling in experiments were in accordance with local university and national guidelines. Hippocampal slices (400-to 450 - $\mu$ m-thick) were prepared from 4- to 6-weekold ICR mice for extracellular synaptic recordings by the procedures described previously (Huang and Hsu, 1999; Huang et al., 1999). In brief, animals were anesthetized with ethyl ether and decapitated, and hippocampal slices were cut from a tissue block of the brain using a Leica VT1000S tissue slicer (Leica, Nussloch, Germany). After their preparation, slices were placed in a holding chamber of artificial CSF (ACSF) oxygenated with $95 \% \mathrm{O}_{2}-5 \% \mathrm{CO}_{2}$ and kept at room temperature for at least $1 \mathrm{hr}$ before recording. The composition of the ACSF solution was (in $\mathrm{mm}$ ): $\mathrm{NaCl} 117, \mathrm{KCl} 4.7, \mathrm{CaCl}_{2} 2.5, \mathrm{MgCl}_{2} 1.2, \mathrm{NaHCO}_{3} 25$, $\mathrm{NaH}_{2} \mathrm{PO}_{4}$ 1.2, and glucose 11 at $\mathrm{pH} 7.3-7.4$ and equilibrated with $95 \%$ $\mathrm{O}_{2}-5 \% \mathrm{CO}_{2}$. In experiments involving pertussis toxin (PTX) treatment, slices were incubated in ACSF solution containing PTX $(5 \mu \mathrm{g} / \mathrm{ml})$ for $\geq 12 \mathrm{hr}$ before recordings following the procedure described previously (Hsu, 1996). Vehicle control preparations were treated with the same protocol in a PTX-free ACSF solution.

Electrophysiological recordings. For the electrophysiological recording, a single slice was then transferred to a submerge-type recording chamber and held between two nylon nets. The chamber consisted of a circular well of a low volume $(1-2 \mathrm{ml})$ and was continuously perfused with oxygenated ACSF at a flow rate of $2-3 \mathrm{ml} / \mathrm{min}$ at $32.0 \pm 0.5^{\circ} \mathrm{C}$. Standard extracellular field recording techniques were used. A bipolar stainless steel stimulating electrode was placed in the stratum granulosum of dentate gyrus to activate mossy fiber afferents at $0.033 \mathrm{~Hz}$. Mossy fiber field EPSPs (fEPSPs) were recorded in the stratum lucidum of the CA3 region of the hippocampus using a glass microelectrode filled with $1 \mathrm{M}$ $\mathrm{NaCl}$ (resistance of 2-3 M $\Omega$ ). The extent of the stratum lucidum was delineated by moving the recording microelectrode in a direction perpendicular to the CA3 pyramidal cell layer until a reversal of mossy fiber fEPSPs could be observed. Because the synaptic response to mossy fiber stimulation could be contaminated by responses activated by disynaptic activation of associational collateral fibers and/or association axon reflex inputs (Weisskopf and Nicoll, 1995), the following procedures were done to minimize the contribution of fibers other than mossy fibers to the fEPSPs (Zalutsky and Nicoll, 1990). First, the stimulating electrode was placed at a site in the granule cell layer of the dentate gyrus in which stimulation of the CA3 stratum lucidum produced the maximal antidromic field potential. Second, the reversal of the waveform as the recording microelectrode was moved from the stratum lucidum to the stratum radiatum served to define mossy fiber inputs. Third, positivities of the mossy fiber fEPSP were minimized, because these may reflect contamination by disynaptic excitatory inputs. Mossy fiber synaptic responses were characterized by fast rise times, by discontinuous stimulusresponse properties, by their elicitation with small stimulus intensity, and by the large-frequency facilitation that occurred when stimulation frequency was changed from 0.033 to $1 \mathrm{~Hz}$ (see Fig. 1A) (Salin et al., 1996). Experiments were included for data analysis only if $\left(2 S, 1^{\prime} S, 2\right.$ prime $\left.] S\right)$ 2-(carboxycyclopropyl)glycine (L-CCG-1) $(10 \mu \mathrm{M})$ or $\left(2 S, 2^{\prime} R, 3^{\prime} R\right)-2$ ( $2^{\prime}, 3^{\prime}$-dicarboxycyclopropyl) glycine (DCG-IV) $(0.5 \mu \mathrm{M})$, the potent group 2 mGluR agonists that selectively block mossy fiber responses, caused a $>80 \%$ reduction in the synaptic responses (Castillo et al., 1997). To stimulate independent inputs to the same cell population, two bipolar stimulating electrodes were positioned on both edges of the stratum granulosum of dentate gyrus to activate two different mossy fiber inputs, alternating every $15 \mathrm{sec}$. Their positions were arranged so that the same amount of current evoked two responses that did not differ from each other by $>10 \%$. The absence of cross-pathway paired-pulse facilitation (PPF) was used to ensure the two inputs were independent of each other. In all experiments, baseline synaptic transmission was monitored for 30 min before drug administration or before delivering either high- or low-frequency stimulation. The strength of synaptic transmission was quantified by measuring the amplitude of fEPSPs. The fEPSP amplitudes were calculated after subtracting the mossy fiber volley from the evoked response. The mossy fiber volley was recorded at the end of experiment after blocking synaptic transmission with 6-cyano-7-nitroquinoxaline-2,3dione (CNQX) $(20 \mu \mathrm{M})$ or 2,3-dioxo-6-nitro-1,2,3,4-tetrahydrobenzo(f) quinoxaline-7-sulfonamide (NBQX) $(20 \mu \mathrm{M})$. LTP was induced by a high-frequency stimulation, at the test pulse intensity, consisting of two $1 \mathrm{sec}$ trains of stimuli at $100 \mathrm{~Hz}$, delivered with an interval of $20 \mathrm{sec}$. D-APV $(50 \mu \mathrm{M})$ was present for the duration of all experiments to block LTP at the CA 3 to CA3 collateral synapses. Depotentiation was induced by application of $15 \mathrm{~min}$ low-frequency trains of stimuli at $1 \mathrm{~Hz}$, and the stimulation intensity was the same as the test pulse intensity. The responses during the trains were not recorded, and for convenience, these periods are not shown on the graph. The values of residual potentiation reported here were calculated as the changes in fEPSP amplitude measured $40 \mathrm{~min}$ after the end of LFS. Microelectrodes were pulled from microfiber $1.0 \mathrm{~mm}$ capillary tubing on a Brown-Flaming electrode puller (Sutter Instruments, San Rafael, CA). Electrical signals were collected with an Axoclamp-2B (Axon Instruments, Foster City, CA) filtered at $1 \mathrm{kHz}$ and sampled at $10 \mathrm{kHz}$, and an Intel Pentium-based computer with pClamp software (Version 7.0; Axon Instruments) was used to on-line acquire and off-line analyze the data.

Drug application. All drugs were applied by dissolving them to the desired final concentrations in the ACSF and by switching the perfusion from control ACSF to drug-containing ACSF. Appropriate stock solutions of drugs were made and diluted with ACSF just before application. CNQX and NBQX were dissolved in dimethylsulfoxide (DMSO) stock solution and stored at $-20^{\circ} \mathrm{C}$ until the day of experiment. The concentration of DMSO in the perfusing medium was $0.05 \%$, which alone had no effect on the basal synaptic transmission ( $n=3$; data not shown). 1-Aminoindan-1,5-dicarboxylic acid (AIDA), $\alpha$-methyl-4-carboxyphenylglycine (MCPG), $(\alpha S)$ - $\alpha$-amino- $\alpha$-(1S,2S)-2-carboxycyclopropyl-9H-xanthine-9propanic acid (LY341495), $\alpha$-methyl- L-2-amino-4-phosphonobutyrate (MAP4), DCG-IV, L-CCG-I, and L-2-amino-4-phosphonobutyric acid (LAP-4) were prepared by first dissolving them in an equimolar amount of $\mathrm{NaOH}$ as a concentrated stock solution and then diluting to their final concentration in ACSF. Pertussis toxin was purchased from Sigma (St. Louis, MO); D-APV, CNQX, NBQX, AIDA, MCPG, LY341495, MAP4, L-AP-4, L-CCG-I, and DCG-IV were obtained from Tocris Cookson (Bristol, UK).

Statistical analysis. The data for each experiment were normalized relative to baseline. Figures show mean \pm SEM. The significance of the difference between the mean was calculated by a paired or unpaired Student's $t$ test. Numbers of experiments are indicated by $n$. Probability values of $p<0.05$ were considered to represent significant differences.

\section{RESULTS}

\section{Identification of mossy fiber synaptic response}

Extracellular field potential recordings were used throughout this study to measure mossy fiber synaptic transmission. In the hippocampal CA3 region, pyramidal neurons receive two anatomically distinct glutamatergic synaptic inputs, a mossy fiber input and an associational-commissural input (Amaral and Witter, 1989). To ensure that the synaptic responses obtained in this study were mainly evoked by mossy fiber inputs, two criteria described previously were used (Salin et al., 1996; Castillo et al., 1997). The typical identification procedures of mossy fiber field potential recorded in stratum lucidum are shown in Figure $1 A$. The first criterion was to test the effect of the group $2 \mathrm{mGluR}$ agonist DCG-IV on fEPSPs by mossy fiber stimulation because it was pointed out that the mossy fiber synapses in the mouse hippocampus possess inhibitory presynaptic group 2 mGluRs, whereas associational-commissural fibers do not have these receptors (Tanabe et al., 1992; Yokoi et al., 1996). As is evident (Fig. $1 A)$, application of DCG-IV $(0.5 \mu \mathrm{M})$ markedly and reversibly inhibited the synaptic response, indicating that the major component of field potential obtained in our study was mossy fiber-evoked responses. The next criterion of mossy fiber synaptic response was characterized by the large-frequency facilitation that occurred when stimulation frequency was increased from 0.033 to $1 \mathrm{~Hz}$. This frequency facilitation behavior was specifically expressed at mossy fiber-CA3 synapses but not at associationalcommissural fibers (Salin et al., 1996). When the stimulus frequency was raised to $1 \mathrm{~Hz}$ for $2 \mathrm{~min}$, the fEPSP was markedly facilitated in amplitude. After the stimulus frequency was re- 


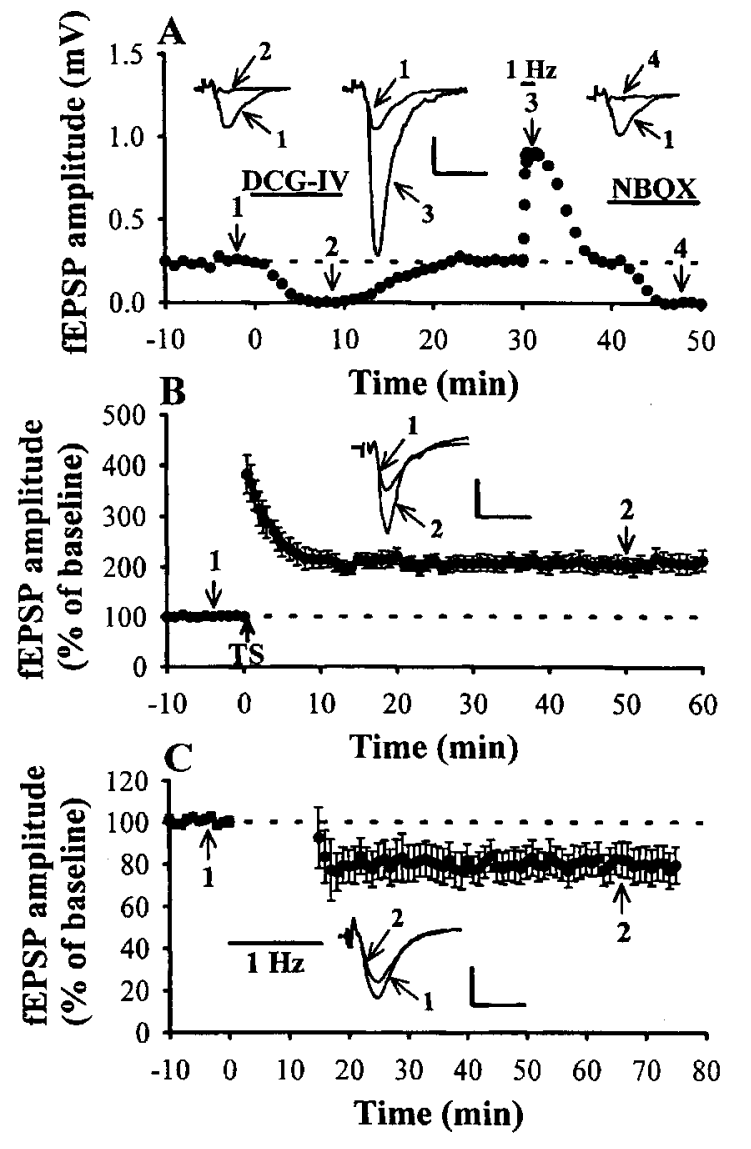

Figure 1. The induction of mossy fiber LTP and LTD. A, An example of pharmacological and physiological characterization of mossy fiber synaptic responses. To stimulate mossy fiber inputs, a bipolar stimulating electrode was placed in the stratum granulosum of dentate gyrus, and extracellular fEPSPs were recorded from the stratum lucidum of the CA3 region. The selective group $2 \mathrm{mGluR}$ agonist DCG-IV was used to confirm that the responses were mediated by mossy fibers. Application of DCG-IV $(0.5 \mu \mathrm{M})$ in the perfusion medium quickly and completely suppressed mossy fiber-evoked fEPSPs. The mossy fiber synapse also exhibits a greater frequency facilitation behavior. Increasing the stimulus frequency from 0.033 to $1 \mathrm{~Hz}$ caused pronounced frequency facilitation. This facilitation was completely reversed upon returning to the control stimulus frequency. At the end of the experiment, NBQX $(20 \mu \mathrm{M})$ was applied. $B$, The time course and magnitude of mossy fiber LTP. Highfrequency TS to the mossy fibers resulted in a large post-tetanic potentiation lasting for several minutes after TS, followed by stable LTP expression $(n=12)$. $C$, Mossy fiber LTD induced by LFS. Summary of nine experiments showing that LFS at $1 \mathrm{~Hz}$ for $15 \mathrm{~min}$ elicits LTD. The superimposed fEPSP in the inset of each graph illustrates respective recordings from example experiments taken at the time indicated by the numbers. All experiments were done in the presence of the NMDA receptor antagonist D-APV $(50 \mu \mathrm{M})$. Upward arrows indicate application of TS. Horizontal bars indicate the period of the delivery of LFS or pharmacological agents as indicated. The horizontal dashed lines indicate the average value of the normalized amplitude during the control period. Calibration: $0.2 \mathrm{mV}, 10 \mathrm{msec}$.

turned to $0.033 \mathrm{~Hz}$, the fEPSP amplitude rapidly decayed to the control baseline level (Fig. 1A). At the end of experiment, $20 \mu \mathrm{M}$ NBQX (non-NMDA receptor antagonist) was added to the bath to make sure that this synaptic response was glutamatergic and to assess the fiber volley component of the response.

\section{Induction of mossy fiber LTP, long-term depression, and depotentiation}

We initially examined whether in the condition of our experiments a brief of high-frequency TS could induce LTP at the mossy fiber-CA3 synapses. As shown in Figure $1 B$, robust LTP in the CA3 region was induced by means of $100 \mathrm{~Hz}$ high-frequency TS of mossy fiber inputs, which persisted as long as recording was continued. The amplitude of fEPSP measured 40 min after TS was $203.3 \pm 15.9 \%$ of baseline $(n=12 ; p<0.05$; paired Student's $t$ test). LTP was induced in the presence of NMDA receptor blocker D-APV $(50 \mu \mathrm{M})$. Having established the condition for inducing LTP at the mossy fiber-CA3 synapses, we next asked whether depotentiating stimulation could disrupt the maintenance of previously established LTP. To establish a reliable depotentiation, a long train of LFS protocol, $1 \mathrm{~Hz} / 900$ pulse stimulation, was used. As reported previously (Domenici et al., 1998; Tzounopoulos et al., 1998), at naive synapses, $1 \mathrm{~Hz} / 900$ pulse stimulation resulted in a significant long-term depression (LTD) of fEPSP (Fig. 1C). On average, the amplitude of fEPSP measured $40 \mathrm{~min}$ after the end of $1 \mathrm{~Hz}$ stimulation was $81.2 \pm$ $7.6 \%$ of baseline ( $n=9 ; p<0.05$; paired Student's $t$ test).

We next examined the effect of LFS on the previously established LTP. As expected, when LFS was applied 1-10 min after, LTP induction caused an immediate depression of the potentiated synaptic responses; this was followed by recovery toward the baseline levels within a few minutes with no additional changes thereafter. To examine the time dependence of the LTP reversal effect by LFS, we varied the time interval between the induction of LTP and the delivery of LFS. Figure 2 summarizes experiments in which LFS was applied $1(A), 10(B)$, or $30(C)$ min after the induction of LTP. As illustrated, when LFS was applied 1 or 10 min after LTP induction, LTP was almost completely reversed. The residual potentiation measured $40 \mathrm{~min}$ after the end of LFS was $111.3 \pm 8.9 \%(n=8)$ and $126.7 \pm 14.5 \%(n=8$ of 10$)$ of baseline, respectively. In contrast, when LFS was delivered 30 min after LTP induction, the magnitude of depotentiation was markedly reduced (Fig. $2 C$ ). The mean residual potentiation measured 40 min after the end of LFS was $176.8 \pm 12.5 \%(n=$ 9) of baseline. Comparison of the effect of LFS applied to naive synapses (LTD) (Fig. 1C) or applied 1, 10, or 30 min after the induction of LTP was summarized in Figure $2 D$, in which the magnitude of the depression measured 40 min after each LFS was calculated relative to the baseline just before each LFS. The magnitude of depotentiation in which LFS was applied 1 min after LTP induction was calculated by comparing the synaptic responses at $40 \mathrm{~min}$ from the experiments illustrated in Figure $2 B$ with the magnitude of LTP at $40 \mathrm{~min}$ from the experiments illustrated in Figure $1 A$. As shown in Figure $2 D$, the magnitude of depotentiation in which LFS was given $1(92.23 \%)$ or $10 \mathrm{~min}$ $(76.4 \pm 14.5 \%)$ after LTP was significantly larger than the LTD elicited at naive synapses $(18.8 \pm 7.5 \% ; p<0.05$; unpaired Student's $t$ test). However, when LFS was given 30 min after LTP induction, the magnitude of depotentiation was the same as for LTD at naive synapses $(29.8 \pm 11.6$ versus $18.8 \pm 7.5 \% ; p>0.05$; unpaired Student's $t$ test). These results suggest that mossy fiber LTP is vulnerable to disruption by depotentiating stimuli within a brief period after its induction. Because the $1 \mathrm{~Hz} / 900$ pulses LFS starting 10 min after LTP induction could effectively reverse LTP, we chose this paradigm to examine the properties of the LFS-induced depotentiation of mossy fiber LTP.

\section{Induction of depotentiation has unsaturated LTP}

Having confirmed the existence of a time-dependent reversal of LTP by LFS at the mossy fiber-CA3 synapses, we next examined whether the synapses that had undergone depotentiation could subsequently exhibit LTP. We adopted the approach used to 
Figure 2. Time-dependent reversal of LTP by LFS. $A-C$, Summary of experiments in which LTP was induced at the mossy fiber-CA3 synapses. LFS (1 Hz, $15 \mathrm{~min})$ was applied at various times after LTP induction: $A, 1$ min delay $(n=8) ; B, 10$ min delay $(n=10)$; or $C, 30 \mathrm{~min}$ delay $(n=7)$. $D$, Histogram comparing effects of LFS applied to naive synapses (LTD) or applied 1, 10, or $30 \mathrm{~min}$ after LTP induction. The data of LTD are taken from Figure $1 C$. The magnitude of LTD was calculated at 40 min after the end of LFS at naive synapses. The magnitude of 1 min delay depotentiation was calculated by comparing the synaptic responses at $40 \mathrm{~min}$ after the end of LFS from the experiments illustrated in $A$ with the magnitude of LTP at $50 \mathrm{~min}$ from the experiments illustrated in Figure $1 B$. Because both sets of data have variance, it is not possible to calculate an SE of this depotentiation value. Statistical analysis using ANOVA indicates that this value is significantly different from LTP at naive synapses $(p<0.05)$. The magnitude of 10 or 30 min delay depotentiation was calculated by comparing the synaptic responses at $40 \mathrm{~min}$ after the end of LFS from the experiments illustrated in $B$ or $C$ with the individual baseline magnitude just before each LFS application. Horizontal bars indi-
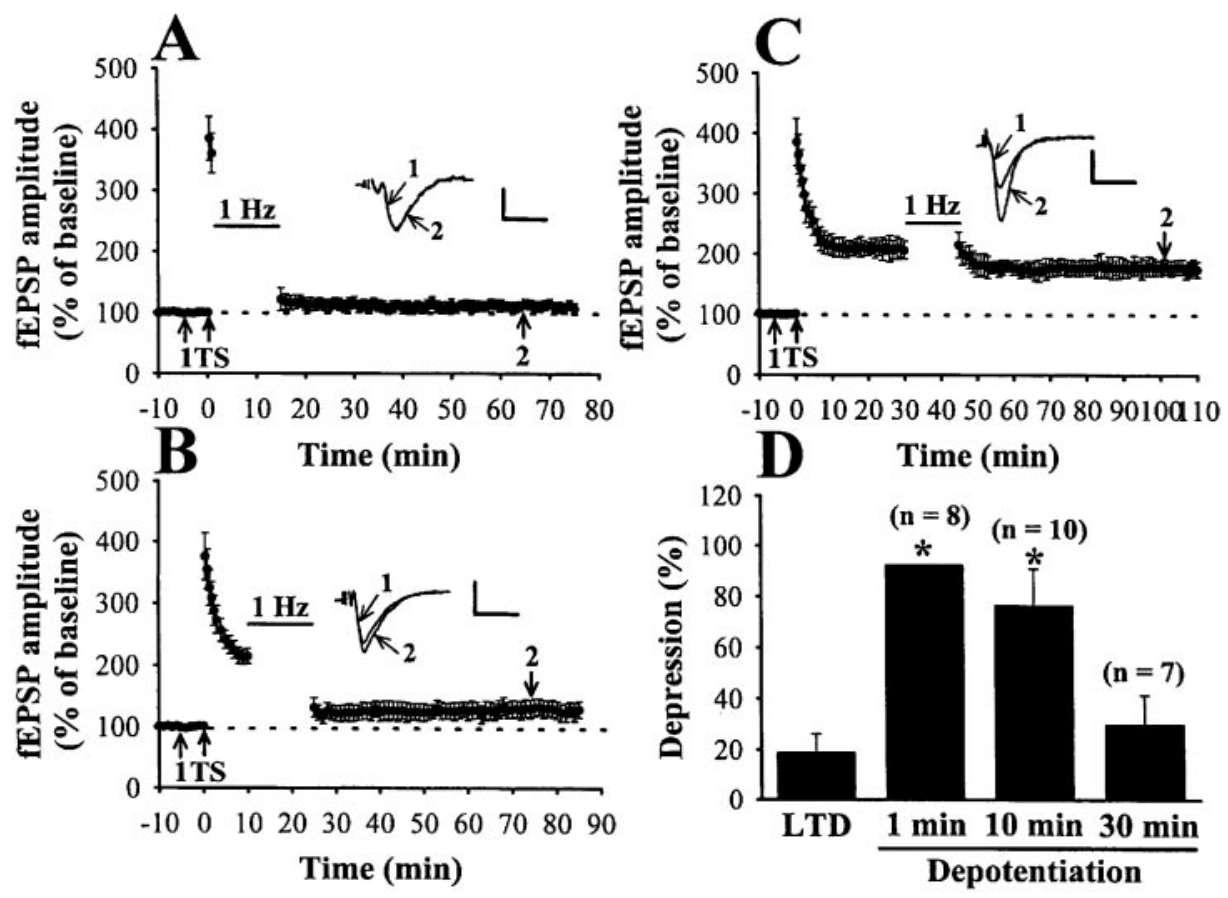

cate the period of the delivery of LFS or pharmacological agents as indicated. Asterisks represent the significant difference from LTD group ( $p<$ 0.05). Calibration: $0.2 \mathrm{mV}, 10 \mathrm{msec}$.

address the same question after induction of homosynaptic LTD at Schaffer collateral-CA1 synapses (Dudek and Bear, 1993; Mulkey et al., 1993). As shown in Figure $3 A$, high-frequency TS led to LTP that stabilized at a value of $212.3 \pm 14.5 \%$ (40 min after TS; $n=6 ; p<0.05$; paired Student's $t$ test) of baseline. In control experiments, a second TS delivered 40 min later increased the fEPSP amplitude by $34.5 \pm 8.7 \%(n=6$; $p<0.05$; paired Student's $t$ test) of baseline. This result indicates that the first TS was sufficient to saturate the LTP. Figure $3 B$ illustrates the experiments that were identical to those in Figure $3 A$, with the only difference that LFS (depotentiating stimulation; $1 \mathrm{~Hz} / 900$ pulses) was delivered 10 min after the first TS. As can be seen from the graph, the second TS that followed LFS caused significantly more LTP than in control experiments $(p<0.05$; unpaired Student's $t$ test) (Fig. $3 B, C$ ). The second TS 40 min later caused the fEPSP amplitude to increase by $98.1 \pm 16.3 \%(n=6)$ of baseline. These results suggest that LFS-induced depotentiation is reversible and has the ability to unsaturate LTP.

\section{Postsynaptic depolarization is not required for the induction of LFS-induced depotentiation}

We next tested whether depolarization in the postsynaptic cells is required for the induction of LFS-induced depotentiation at the mossy fiber-CA3 synapses by using kynurenic acid (20 mM), which blocks both NMDA and non-NMDA receptors (Kemp et al., 1988; Watkins et al., 1990). As can be seen in Figure 4A, application of kynurenic acid (20 mM) quickly and completely blocked synaptic transmission, and responses recovered quickly after washout of this antagonist. After complete blockade of synaptic responses with kynurenic acid, high-frequency TS was applied and LFS was given $10 \mathrm{~min}$ after the TS. After washout of kynurenic acid, the fEPSP recovered to near-baseline level. On average, the fEPSP amplitude measured $40 \mathrm{~min}$ after the end of LFS was $121.3 \pm 20.8 \%(n=6)$ of baseline, which was not significantly different from that of depotentiation recorded under control condition $(126.7 \pm 14.5 \% ; p>0.05$; unpaired Student's $t$ test). Nonetheless, the possibility remained that, in the presence of kynurenic acid, the induction of LTP by high-frequency TS is blocked. Arguing against this possibility was the observation illustrated in Figure 4B, that LTP was exhibited upon washout of kynurenic acid in the control experiments. The magnitude of LTP was indistinguishable from control (control, $203.3 \pm 15.9 \%$ of baseline; kynurenic acid, $187.9 \pm 18.5 \% ; n=6 ; p>0.05$; unpaired Student's $t$ test). These results suggest that neither postsynaptic activity nor the ionotropic glutamate receptors was required for the induction of mossy fiber LFS-induced depotentiation.

\section{LFS-induced depotentiation is not input specific}

The following experiment was designed to investigate whether LFS-induced depotentiation at the mossy fiber-CA3 synapses is input specific (or homosynaptic). To address this issue, two stimulating electrodes were placed on both edges of the stratum granulosum of dentate gyrus to activate two groups of inputs to the same cell population. As a typical example illustrated in Figure $5 A$, independence of inputs activated by the two stimulating electrodes was assessed by verifying the absence of heterosynaptic facilitation between the two inputs using paired stimuli applied at $30 \mathrm{msec}$ interval. Having confirmed the independence of afferents activated, LTP was induced by a high-frequency TS to both pathways simultaneously; this was followed by a $1 \mathrm{~Hz} / 900$ pulses LFS to only one (test) pathway to reverse LTP. This resulted in homosynaptic depotentiation in the test pathway but also in a progressive heterosynaptic reversal of LTP induced on the control, separate pathway (Fig. $5 B$ ). This phenomenon was observed in all six slices tested in this study. At the control pathway, the mean residual potentiation measured $40 \mathrm{~min}$ after the end of LFS was $149.6 \pm 11.32 \%(n=6)$ of baseline (Fig. $5 C)$, which was not significantly different from the residual potentiation at test pathway $(136.5 \pm 25.63 \%$ of baseline; $n=6 ; p>0.05$; unpaired Student's $t$ test) after receiving LFS. These results indicated that the reversal of LTP by LFS is not specific to the 

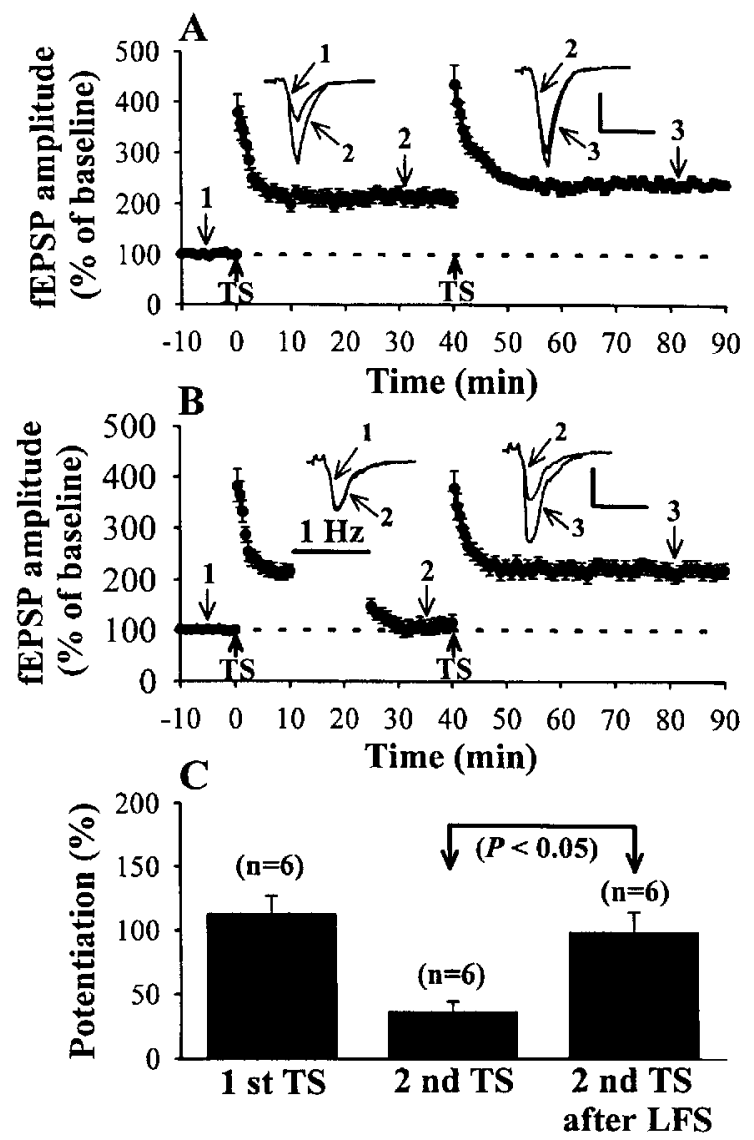

Figure 3. The depressed synapses can be potentiated. A, Summary of six experiments in which TS was applied twice with a 40 min interval. Note that the first TS nearly saturates the LTP; little additional potentiation is caused by a second TS. $B$, Summary of six experiments identical to those shown in $A$ with the exception that LFS ( $1 \mathrm{~Hz}, 15 \mathrm{~min}$ ) was delivered 10 min after the first TS. In this case, subsequent TS 40 min later was able to reverse the synaptic depression caused by LFS. $C$, Summary data in which the magnitude of the potentiation measured 40 min after each TS was calculated relative to the baseline period before each TS applied. In control experiments, as illustrated in $A$, we found that the first TS produced a potentiation of $112.3 \pm 14.5 \%$ above baseline, whereas the second TS produced an additional increase of only $34.5 \pm 8.7 \%$. In the experiments shown in $B$, in which the second TS followed LFS, it caused a potentiation of $98.1 \pm 16.3 \%$ above baseline $(p<0.05)$. Calibration: 0.2 $\mathrm{mV}, 10 \mathrm{msec}$.

synapses receiving the stimulation. In other words, LFS-induced depotentiation at the mossy fiber-CA3 synapses is not only homosynaptic but also heterosynaptic.

\section{Effect of mGluR antagonism on LFS-induced depotentiation}

Based on experiments using mutant mice and pharmacological antagonists, it has been proposed that mGluRs play an essential role in the development of both LTP and LTD at the mossy fiber-CA3 synapses in the hippocampus (Ito and Sugiyama, 1991; Kobayashi et al., 1996; Yokoi et al., 1996; Tzounopoulos et al., 1998). To assess the role of mGluRs in triggering depotentiation, we performed a series of experiments in which we analyzed the effects of mGluR antagonists on the development of LFS-induced depotentiation. Figure 6 summarizes our pharmacological examination of depotentiation. Initially, to assess the role of group 1 mGluRs in the LFS-induced depotentiation, the selective group 1 antagonist AIDA was applied during the delivery of LFS. Under
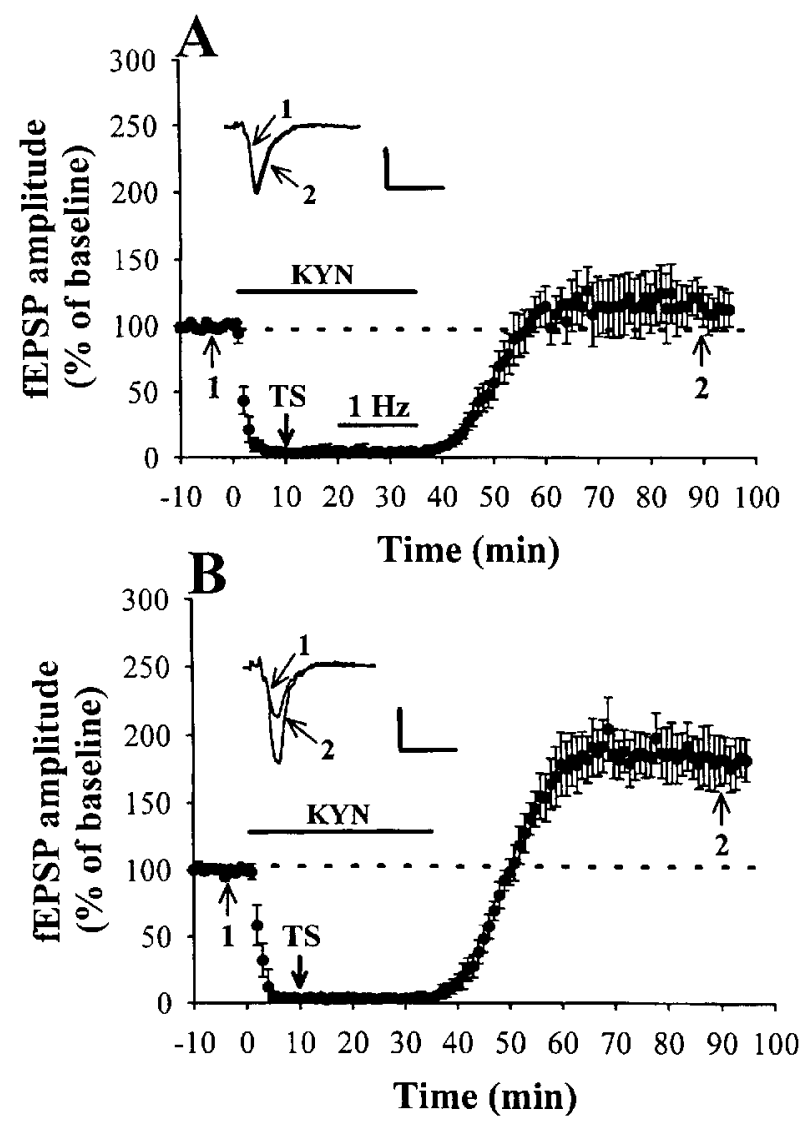

Figure 4. Postsynaptic ionotropic glutamate receptor activation is not required for the induction of LFS-induced depotentiation. $A$, The time course of experiments in which mossy fiber depotentiation was induced in the absence of excitatory synaptic transmission. After complete blockade of fEPSPs with kynurenic acid $(K Y N ; 20 \mathrm{~mm})$, high-frequency TS was applied, and LFS was given 10 min after TS. Washout of kynurenic acid was started at the end of LFS. Note that, after washout of kynurenic acid, the fEPSPs recovered to near-baseline level $(n=6)$. $B$, Summary of six experiments identical to those shown in $A$, with the exception that LFS was not delivered after TS. In this case, the synaptic responses exhibited LTP after washout of kynurenic acid. Horizontal bars indicate the period of the delivery of LFS or kynurenic acid. Calibration: $0.2 \mathrm{mV}, 10 \mathrm{msec}$.

this condition, we did not see any effect of AIDA $(250 \mu \mathrm{M})$ on the depotentiation; the level of depotentiation did not differ from the control values ( $p>0.05$; unpaired Student's $t$ test) (Fig. 6A). The residual potentiation measured 40 min after the end of LFS was $124.6 \pm 10.4 \%(n=6)$ of baseline. We next tested the effect of group 2 antagonists on the LFS-induced depotentiation. As shown in Figure $6, B$ and $C$, when the nonselective group 2 antagonist MCPG $(250 \mu \mathrm{M})$ or the selective group $2 \mathrm{mGluR}$ antagonist LY341495 (3 $\mu \mathrm{M})$ was applied during LFS, the depotentiation of LTP was completely abolished ( $p<0.05$; unpaired Student's $t$ test). The residual potentiation measured $40 \mathrm{~min}$ after the end of LFS was $203.7 \pm 11.9 \%(n=6)$ and $213.8 \pm 17.8 \%$ $(n=6)$ of baseline, respectively. Finally, we examined the effect of the group 3 antagonist MAP4 $(100 \mu \mathrm{M})$ on the LFS-induced depotentiation. As Figure $6 D$ illustrates, MAP4 also exerted a partial but significant inhibition of the LFS-induced depotentiation. The residual potentiation measured $40 \mathrm{~min}$ after the end of LFS was $148.9 \pm 12.5 \%(n=8 ; p<0.05$; unpaired Student's $t$ test) of baseline. These results suggest that the activation of group 2 and/or group 3 mGluRs is an absolute requirement for the LFS-induced depotentiation at the mossy fiber-CA3 synapses. 


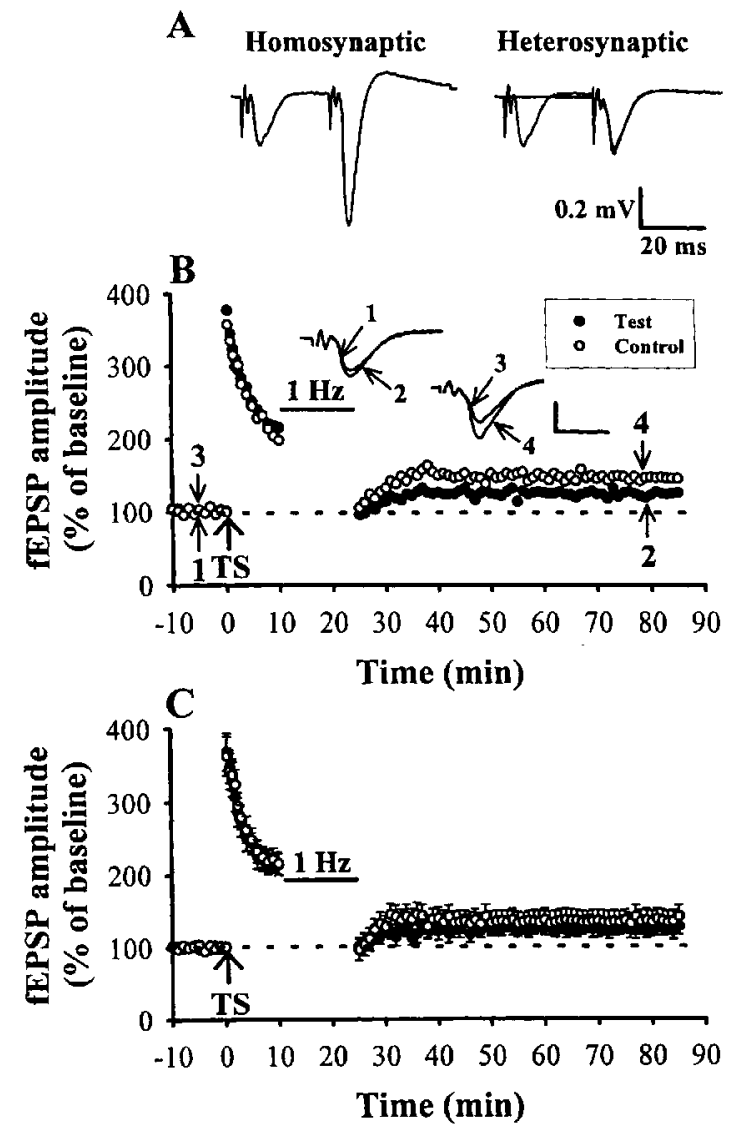

Figure 5. Heterosynaptic reversal of LTP by LFS. A, An example showing that two stimulatory electrodes were used to activate two independent groups of afferents. Field EPSPs were evoked by paired stimulations applied at $30 \mathrm{msec}$ intervals to the first and/or second afferents. Pairedpulse facilitation was present when stimuli were applied twice to the same afferent (homosynaptic facilitation) but not when the stimuli were applied to different afferents (no heterosynaptic facilitation). B. Example of an experiment showing that LTP was first induced on two afferents by coactivation, followed by LFS ( $1 \mathrm{~Hz}, 15 \mathrm{~min})$ applied to only one afferent (test pathway). This resulted in a homosynaptic reversal of LTP at the test pathway but also in a heterosynaptic reversal of LTP induced previously at the other control pathway. The superimposed fEPSP in the inset illustrates respective recordings from example experiments taken at the time indicated by numbers. Horizontal bars denote the period of the delivery of LFS. Calibration: $0.5 \mathrm{mV}, 10 \mathrm{msec}$. $C$, Summary of data from six experiments performed as in $B$.

\section{Activation of group 2 but not group 3 mGluRs mimics LFS-induced depotentiation}

To further establish that the LFS-induced depotentiation is mediated through the activation of group $2 \mathrm{mGluRs}$, it is essential to demonstrate that LFS-induced depotentiation should be mimicked by the direct activation of group 2 mGluRs. For this purpose, the effect of the activation of group 2 mGluRs by direct application of the selective group 2 agonist DCG-IV on the development of LTP was investigated. Initially we attempted to induce LTD by bath applying low concentrations of DCG-IV. We failed to observe any lasting effects of brief applications of 0.5 or $1 \mu \mathrm{M}$ DCG-IV (Yokoi et al., 1996); however, a 5 min application of $5 \mu \mathrm{M}$ DCG-IV consistently produced a long-lasting depression of the evoked synaptic responses that lasted for over $1 \mathrm{hr}$ after washout of the DCG-IV (Fig. 7A). On average, the fEPSP amplitude measured 40 min after washout of DCG-IV was $83.5 \pm$ $7.5 \%(n=6 ; p<0.05$; paired Student's $t$ test $)$ of baseline. In the next experiments, DCG-IV was applied $10 \mathrm{~min}$ after the induction of LTP. As shown in Figure 7B, the reversal of LTP similar to LFS application was observed with administration of DCG-IV beginning $10 \mathrm{~min}$ after LTP induction. Application of DCG-IV for 5 min exerted a significant suppression of fEPSP. After washout of DCG-IV, the fEPSP recovered to near the pretetanus baseline. On average, the fEPSP amplitude measured $40 \mathrm{~min}$ after washout of DCG-IV was $110.1 \pm 11.3 \%(n=8)$ of baseline. In contrast, when DCG-IV was applied 30 min after LTP induction, the synaptic responses consistently recovered to the potentiated level; i.e., the amplitude of fEPSP measured $40 \mathrm{~min}$ after DCG-IV washout was $178.3 \pm 12.9 \%(n=6)$ of baseline (Fig. $7 C)$. Comparison of the effect of DCG-IV applied to naive synapses (DCG-IV LTD) or applied 10 or 30 after the induction of LTP was summarized in Figure $7 D$, in which the magnitude of the depression measured 40 min after washout of DCG-IV was calculated relative to the baseline just before DCG-IV application. As shown in Figure $7 D$, the magnitude of depotentiation in which LFS was given 10 min $(111.3 \pm 15.3 \%)$ after LTP was significantly larger than the DCG-IV LTD elicited at naive synapses $(16.5 \pm 7.0 \% ; p<0.05$; unpaired Student's $t$ test $)$. However, when DCG-IV was given $30 \mathrm{~min}$ after LTP induction, the magnitude of depotentiation was the same as for DCG-IV LTD at naive synapses $(37.5 \pm 12.4$ versus $16.5 \pm 7.0 \% ; p>0.05$; unpaired Student's $t$ test). Moreover, preincubation with $3 \mu \mathrm{M}$ LY341495 completely prevented establishment of DCG-IVinduced LTD $(n=3$; data not shown) and depotentiation $(n=3$; data not shown), confirming that the DCG-IV is acting at group $2 \mathrm{mGluRs}$ to produce the synaptic depression. These results also suggest that direct activation of group 2 mGluRs can reveal a time-dependent reversal of mossy fiber LTP.

Because our above experiments have shown that the group 3 mGluR antagonist MAP4 may also impair the LFS-induced depotentiation, we next evaluated whether group 3 mGluRs contribute to depotentiation. If the activation of group $3 \mathrm{mGluRs}$ is involved in LFS-induced depotentiation, direct activation of group 3 mGluRs by agonist should be able to reverse LTP in the same way as LFS did. Attempts were made to see whether the selective group 3 agonist L-AP-4 could effectively reverse LTP. Initially, we examined the effect of L-AP-4 $(50 \mu \mathrm{M})$ on the basal synaptic transmission. Application of L-AP-4 alone for $5 \mathrm{~min}$ had no significant effect on the baseline synaptic transmission. The amplitude of fEPSP was $102.8 \pm 5.6 \%(n=5)$ of baseline at $5 \mathrm{~min}$ after L-AP-4 application. After washout of L-AP-4, the synaptic response remains normal. We then performed experiments in which L-AP-4 was applied 10 min after the induction of LTP. In all six experiments tested, it caused no reliable change in potentiated synaptic responses. On average, the fEPSP amplitude measured 40 min after washout of L-AP-4 was $214.5 \pm 12.4 \%(n=6)$ of baseline, which was not significantly different from the LTP measured in control slices without L-AP-4 administration (203.3 $\pm 15.9 \%$ of baseline; $n=12 ; p>0.05$; unpaired Student's $t$ test) (Fig. $1 B$ ). These results suggest that the activation of group 3 mGluRs is not required for the LFS-induced depotentiation at the mossy fiber-CA3 synapses.

\section{Pertussis toxin-sensitive $\mathrm{G}_{\mathrm{i} / \mathrm{o}}$-proteins contribute to LFS-induced depotentiation}

It has been claimed that the group $2 \mathrm{mGluRs}$ are linked to PTX-sensitive $\mathrm{G}_{\mathrm{i} / \mathrm{o}}$-proteins, which inhibit adenylyl cyclase and thereby reduce cAMP formation (Tanabe et al., 1992). Thus, $\mathrm{G}_{\mathrm{i} / \mathrm{o}}$-protein-coupled signaling cascade could be involved in the 

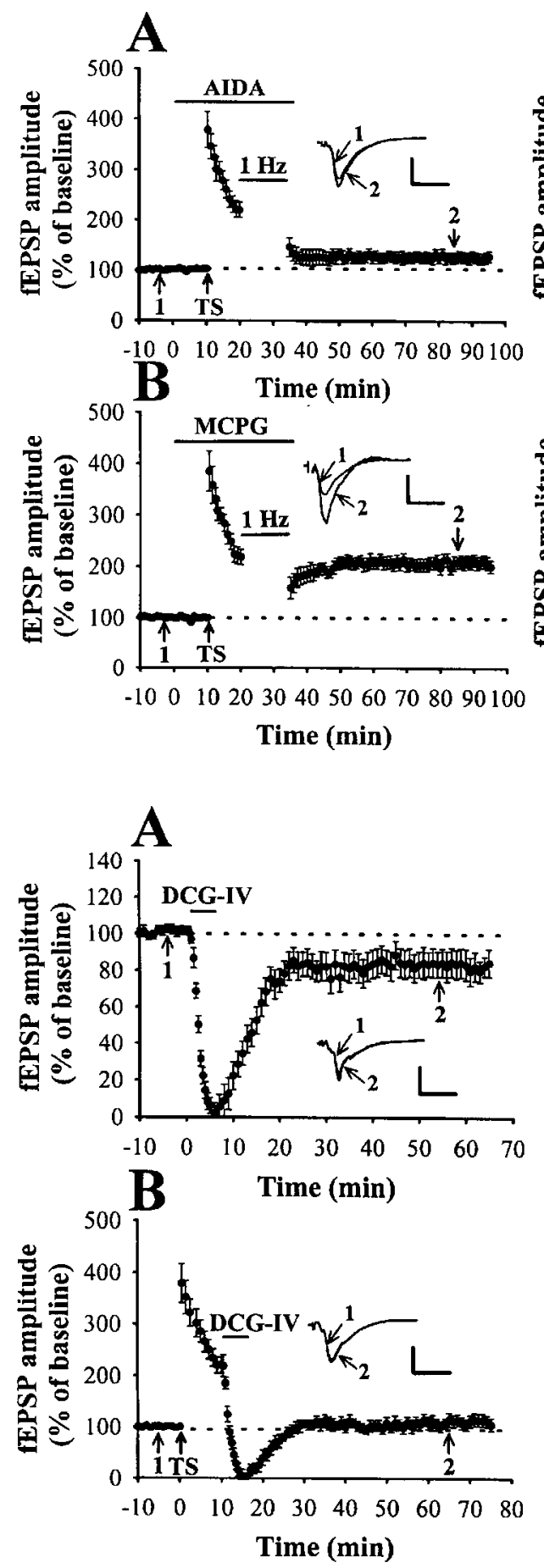
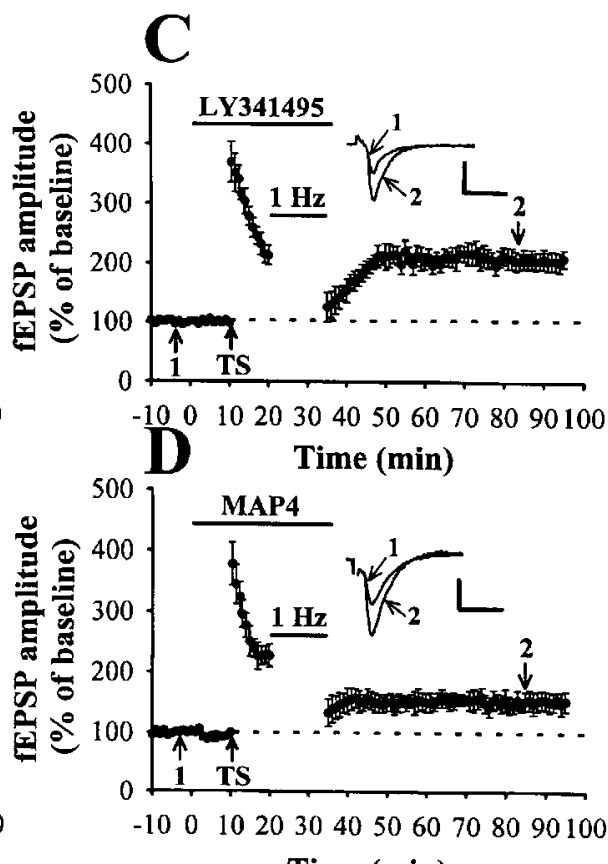

$-100 \quad 102030405060708090100$ D Time (min)

Time (min)
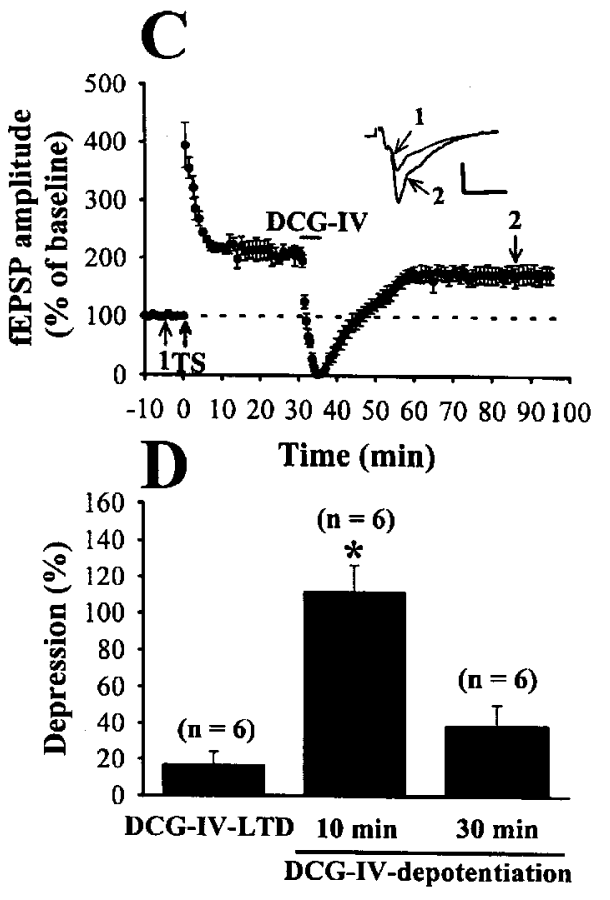

Figure 6. Application of group 2 mGluR antagonists selectively prevents the LFS-induced depotentiation. $A$, Summary of six experiments in which the group $1 \mathrm{mGluR}$ antagonist AIDA $(250 \mu \mathrm{M})$ was applied $10 \mathrm{~min}$ before and left until the end of LFS. AIDA does not affect the LFS-induced depotentiation. $B$, Summary of six experiments in which LFS-induced depotentiation was inhibited by the nonselective group 2 mGluR antagonist MCPG $(250 \mu \mathrm{M})$. $C$, Pooled data from six experiments in which application of the selective group 2 mGluR antagonist LY341495 (3 $\mu \mathrm{M})$, before TS and left until the end of LFS, results in an inhibition of the induction of LFS-induced depotentiation. $D$, Summary of eight experiments in which LFS-induced depotentiation was partially but significantly inhibited by the group $3 \mathrm{mGluR}$ antagonist MAP4 $(100 \mu \mathrm{M})$. Note that only group 2 mGluR antagonists could completely block the LFS-induced depotentiation. Horizontal bars indicate the period of the delivery of LFS or pharmacological agents as indicated. Calibration: $0.5 \mathrm{mV}, 10 \mathrm{msec}$.
Figure 7. Time-dependent reversal of LTP can be induced by the bath-applied group 2 mGluR agonist DCG-IV. A, Application of DCG-IV $(5 \mu \mathrm{M})$ for $5 \mathrm{~min}$ in the bath medium caused LTD that lasted over 60 min after washout of agonist $(n=6)$. $B, C$, DCG-IV $(5 \mu \mathrm{M})$ was applied at various times after LTP induction: $B, 10$ min after $(n=8)$; or $C, 30$ min after $(n=6) . D$, Histogram compares the effect of DCG-IV applied to naive synapses (DCG-IV$L T D$ ) or applied 10 or 30 min after LTP induction. The magnitude of DCG-IV LTD was calculated at 40 min after washout of DCG-IV at naive synapses. The magnitude of 10 or $30 \mathrm{~min}$ delay DCG-IV-induced depotentiation was calculated by comparing the synaptic responses at $40 \mathrm{~min}$ after washout of DCG-IV from the experiments illustrated in $B$ or $C$ with the individual baseline magnitude just before DCG-IV application. Note that DCG-IV erased potentiation when delivered $10 \mathrm{~min}$ after the TS but was without effect when applied $30 \mathrm{~min}$ after. Calibration: $0.5 \mathrm{mV}, 10 \mathrm{msec}$.
LFS-induced depotentiation. This possibility was examined by the pretreatment of the slices with PTX $(5 \mu \mathrm{g} / \mathrm{ml})$ for $12 \mathrm{hr}$ to inhibit the function of PTX-sensitive $\mathrm{G}_{\mathrm{i} / \mathrm{o}}$-proteins (Hsu, 1996). In the vehicle control group, slices were incubated with the normal ACSF alone for at least $12 \mathrm{hr}$ before recording. The results of LFS action on the previously established LTP of vehicle- and PTX-treated slices are summarized in Figure 8. As shown, when LFS was delivered 10 min after, LTP induction caused no reliable change in potentiated synaptic responses in the PTX-treated slices. The mean residual potentiation measured 40 min after the end of LFS was $178.7 \pm 13.2 \%(n=5)$ of baseline. However, in slices taken from the vehicle group, LFS was still able to effectively reverse LTP. The mean residual potentiation measured 40 min after the end of LFS was $126.3 \pm 9.6 \%(n=5)$ of baseline. These results suggest that the LFS-induced depotentiation at the mossy fiber-CA3 synapses is mediated via a PTXsensitive $\mathrm{G}_{\mathrm{i} / \mathrm{o}}$-protein-coupled signaling pathway.

\section{Depotentiation reverses the reduction of PPF during LTP expression}

We further characterized the location of LFS-induced depotentiation expression (presynaptic or postsynaptic) by testing its effect on PPF. When the excitatory afferents to the central neurons are activated twice at intervals of tens of milliseconds 


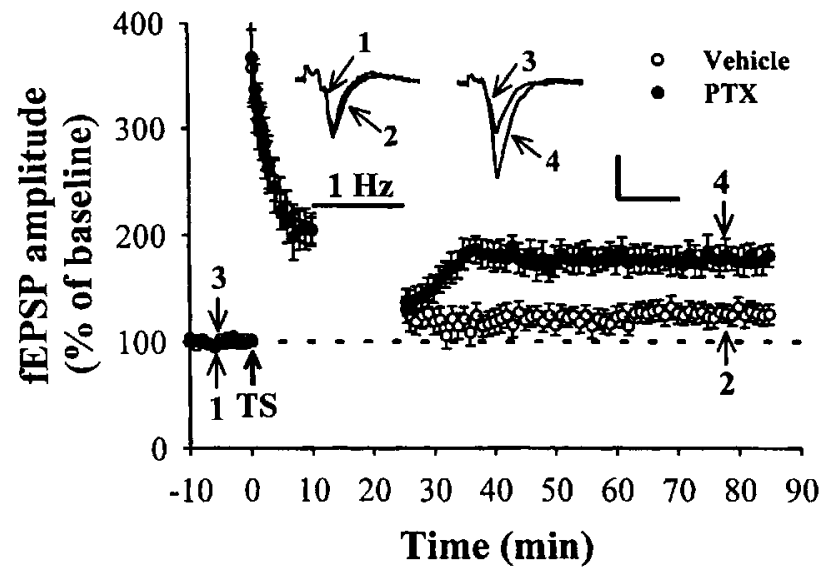

Figure 8. PTX pretreatment blocks the induction of LFS-induced depotentiation. Mossy fiber fEPSP amplitude plotted as a function of time for each evoked potential observed during the course of experiments examining depotentiation induction by LFS in control vehicle- $(n=5)$ or PTX- $(5 \mu \mathrm{g} / \mathrm{ml})$ pretreated slices $(n=5)$. LTP could be successfully induced by high-frequency TS in all tested control vehicle- and PTXpretreated slices, whereas the induction of LFS-induced depotentiation is impaired in PTX-pretreated slices. Calibration: $0.5 \mathrm{mV}, 10 \mathrm{msec}$.

between each stimulus, the response to the second stimulus is generally facilitated in relation to the initial stimulus. This phenomenon is called PPF and is attributed to an increase of the amount of transmitter release to the second stimulus (Zucker, 1989). Thus, manipulations that affect transmitter release may interact strongly with PPF. At the mossy fiber-CA3 synapses, it has been shown that LTP is presynaptic and is accompanied by a persistent depression of PPF (Salin et al., 1996; Son and Carpenter, 1996). If the location of LFS-induced depotentiation expression involved a presynaptic mechanism of action, the reduction of PPF during LTP expression should be reversed after subsequent LFS application. In agreement with previous studies (Salin et al., 1996; Son and Carpenter, 1996), we found that LTP at mossy fibers is accompanied by a persistent reduction of PPF. As shown in Figure 9, the reduction in PPF was very large during the initial minute after tetanic stimulation. During the stable LTP expression, PPF was significantly reduced. On average, the PPF ratio 10 min after LTP induction was reduced from $1.96 \pm 0.07$ to $1.52 \pm$ 0.06 ( $n=6$; $p<0.05$; paired Student's $t$ test). When LFS was delivered $10 \mathrm{~min}$ after, LTP induction significantly reversed PPF attenuation close to baseline values. The average PPF ratio 40 min after the end of LFS was $1.92 \pm 0.09$, which was not significantly different from the baseline PPF ratio $(1.96 \pm 0.07$; $p>0.05$; paired Student's $t$ test). These results suggest that the expression of LFS-induced depotentiation at the mossy fiber-CA3 synapses is presynaptic.

\section{DISCUSSION}

In this study, we have shown that, as with Hebbian forms of LTP occurring at Schaffer collateral-CA1 synapses, non-Hebbian forms of mossy fiber LTP could be reversed by the depotentiating stimulation in a time-dependent manner. There are six principal observations emerged from this work. First, this effect is time dependent. Thus, the magnitude of reversal of LTP by LFS is inversely proportional to the time lag of depotentiating stimulation after LTP induction. Second, the reversal of LTP by LFS is reversible and has the ability to unsaturate LTP. Third, the induction of depotentiation on one potentiated pathway is asso-

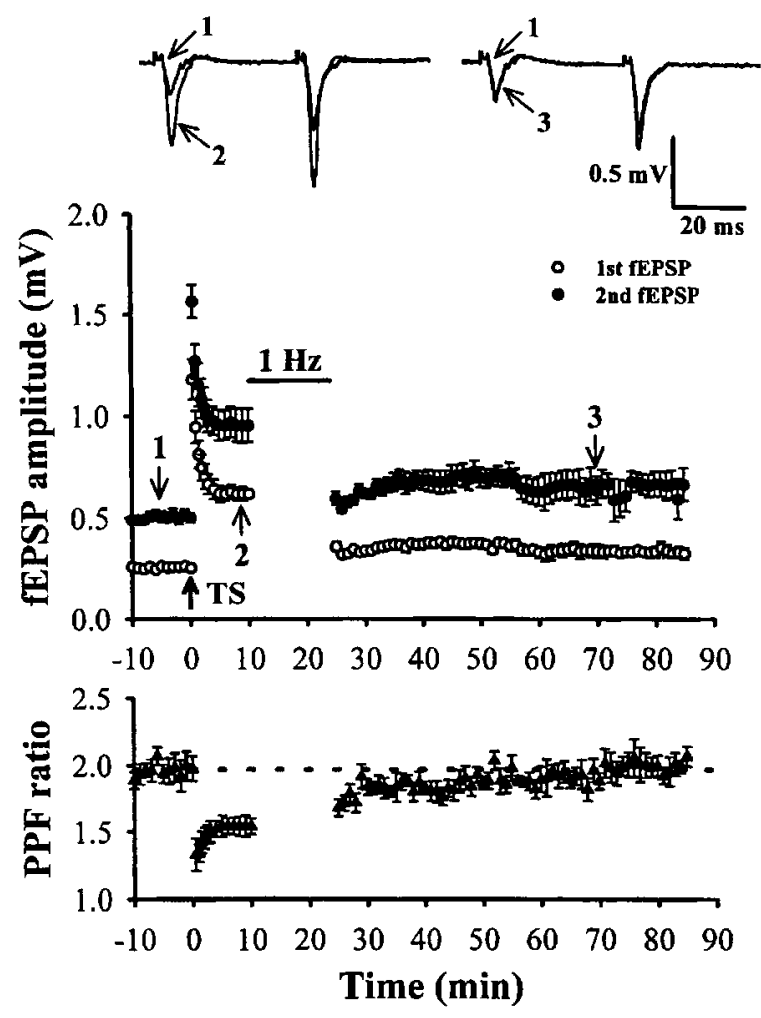

Figure 9. LFS-induced depotentiation reverses the reduction of PPF during LTP expression. TS-induced LTP is accompanied by attenuation of PPF. When LFS was delivered $10 \mathrm{~min}$ after, LTP induction significantly reversed PPF attenuation close to baseline values. Effects of TS and LFS on the PPF ratio calculated from the amplitude of the second of two fEPSPs divided by the first fEPSP amplitude to paired-pulse stimulation at an interstimulus interval of $40 \mathrm{msec}$. The superimposed fEPSPs in the top panel illustrate respective recordings from example experiments taken at the time indicated by numbers.

ciated a heterosynaptic reversal of the LTP induced previously on a separate pathway. Fourth, neither postsynaptic depolarization nor the ionotropic glutamate receptors is required for the depotentiation induction. Fifth, the reversal of LTP by LFS was mimicked by extracellular application of the group $2 \mathrm{mGluR}$ agonist DCG-IV and was blocked by group $2 \mathrm{mGluR}$ antagonists MCPG and LY341495 but not by the group $1 \mathrm{mGluR}$ antagonist AIDA. Sixth, PTX inactivation of $\mathrm{G}_{\mathrm{i} / \mathrm{o}}$-proteins prevents the induction of LFS-induced depotentiation.

Input specificity is a characteristic feature of many types of activity-dependent synaptic plasticity. For example, both mossy fiber LTP and LTD exhibit strong synapse specificity, because the potentiation or depression is restricted to the activated inputs and not in nonactivated inputs, although they terminated onto the same postsynaptic neurons (Higashima and Yamamoto, 1985; Zalutsky and Nicoll, 1992; Kobayashi et al., 1996) (but see Derrick and Martinez, 1996). We now show, however, that there is existence of a heterosynaptic reversal of LTP at the mossy fiber-CA3 synapses. What mechanism might give rise to this heterosynaptic nature of depotentiation? Although it is difficult, based on the present data, to estimate the exact mechanism for this process, a plausible mechanism is a heterosynaptic activation of group 2 mGluRs by spillover of glutamate from neighboring synapses that underwent depotentiation. Indeed, it has been demonstrated that mGluRs at this synapse can be activated by the spread of glutamate out of the synaptic cleft (Vogt and Nicoll, 
1999). However, we could not exclude the possibility that the induction of depotentiation involves the activation of some "longdistance" diffusible messengers that interfere with functioning of adjacent potentiated synapses. However, what kind of diff usible messengers that transmit the signal between separate synapses remains to be elucidated. The functional and physiological relevance of this heterosynaptic reversal of LTP remains unclear; however, this form of synaptic plasticity may prove to be important in the increasing sparseness of the input signal and thereby increase the storage capacity of neuronal circuit.

mGluRs are a class of G-protein-coupled receptors and produce a variety of effects depending on the subtype of receptor activated (Anwyl, 1999). It was shown previously that mGluRs are significantly involved in the induction of LFS-induced depotentiation in the dentate gyrus (Kulla et al., 1999) and CA1 region of the hippocampus (Bashir and Collingridge, 1994) (but see Selig et al., 1995). Moreover, based on experiments using mutant mice and pharmacological antagonists, it has been proposed that mGluRs play a pivotal role in mediating the induction and expression of mossy fiber LTP and LTD (Conquet et al., 1994; Kobayashi et al., 1996; Yokoi et al., 1996) (but see Hsia et al., 1995), but it has not been demonstrated previously that depotentiation is also mediated by the mGluR activation. Given that LFS-induced depotentiation was prevented by the nonselective group 2 mGluR antagonist MCPG and selective group 2 mGluR antagonist LY341495 and was mimicked by bath-applied potent group 2 mGluR agonist DCG-IV, we suggest that activation of group 2 mGluRs may contribute to the induction of mossy fiber depotentiation. Although LY341495 is the most potent antagonist yet reported at group 2 mGluRs (Doherty et al., 2000), it may inhibit other mGluR subtypes at micromolar concentrations. Thus, it may be argued that the concentration of LY341495 used in this study was high enough to affect other classes of mGluRs. Because the group $1 \mathrm{mGluR}$ selective antagonist AIDA had no effect on the LFS-induced depotentiation and because the group 3 mGluR antagonist MAP4 produced only a minor inhibition of depotentiation at a concentration up to $100 \mu \mathrm{M}$, we therefore assumed that the predominant effect of LY341495 was mediated via activation of group 2 mGluRs. These observations are consistent with the presence of a population of group 2 mGluRs in the presynaptic elements of hippocampal mossy fiber-CA3 synapses (Yokoi et al., 1996). Surprisingly, we have found that the group 3 mGluR antagonist MAP4 also attenuates the LFSinduced depotentiation; however, pharmacological activation of group 3 mGluRs by L-AP-4 could not effectively reverse LTP in the same way as LFS. One possible explanation may be that the effect of MAP4 on depotentiation is caused by its nonspecificity. This conclusion is supported by recent findings that the concentration of MAP4 used in this study affects not only group 3 but also group 2 mGluRs (Gomeza et al., 1996).

How might group 2 mGluR activation reverse the previously established LTP? A most likely possibility is that a decrease in presynaptic cAMP concentration contributes to this process. Activation of group $2 \mathrm{mGluRs}$ is known to inhibit the production of cAMP via the activation of a PTX-sensitive $\mathrm{G}_{\mathrm{i} / \mathrm{o}}$-protein (Pin and Duvoisin, 1995). The decrease in cAMP could, in turn, reduce the PKA activity, which has been identified as an important regulator of mossy fiber LTP (Nicoll and Malenka, 1995). Furthermore, recent work has demonstrated that presynaptic phosphorylation of the downstream effectors (rabphilin or Rim) of rab3A is necessary for the expression of mossy fiber LTP (Lonart et al., 1998). This observation pointed to the possibility that dephosphorylation of rabphilin and/or Rim may contribute to the expression of depotentiation.

As in the case for mossy fiber LTP (Ito and Sugiyama, 1991; Castillo et al., 1994) and LTD (Kobayashi et al., 1996), the induction of LFS-induced depotentiation was not influenced by blockade of postsynaptic activity or ionotropic glutamate receptors (Fig. 4), which suggests that LFS-induced depotentiation is attributed to presynaptic mechanisms. This idea is also supported by the finding that the reversal of previously established LTP by LFS stimulation is accompanied by a marked reduction of PPF attenuation during LTP (Fig. 9). Taking all of these results together, we conclude that mossy fiber depotentiation is induced presynaptically. Moreover, we found that LTP can be completely reversed if LFS is applied immediately or 10 min after the induction of LTP but is only partially reversed if this same pattern of synaptic stimulation is applied $30 \mathrm{~min}$ later. This time window for the reversal of LTP reported here supports the idea that biochemical processes that contribute to convert the initial potentiation into a persistent and not readily disrupted state required many minutes to reach completion.

Another important question raised from this study is that whether the depotentiation and LTD represent the same phenomenon. Although both depotentiation and LTD are induced by the same stimulation paradigm, there are some discrepancies among these two phenomena. For example, mossy fiber LTD was shown to be homosynaptic (Kobayashi et al., 1996), whereas depotentiation was found to be both homosynaptic and heterosynaptic (Fig. 5). In addition, unlike LTD, depotentiation is dependent on both the current state of synaptic strength and the time interval after the induction of LTP (Figs. 1, 2). Moreover, LTD appears to be age dependent and more reliable in young animals (Bear and Malenka, 1994), whereas depotentiation is robust in both young and adult animals (Huang and Hsu, 2001). Despite these differences, LTD and depotentiation also shares certain formal similarities. Both LTD and depotentiation are induced by a long train of LFS, are reversible, and require mGluR activation for their induction (Figs. 3, 6) (Kobayashi et al., 1996). Together, the above findings favor the assumption that LTD and depotentiation only share some common mechanisms but are not two identical phenomena.

Because not all LTP at the mossy fiber-CA3 synapses is non-Hebbian (Henze et al., 2000), our findings may apply only to the non-Hebbian form of LTP at that synapses. What might be the functional implications of LFS-induced depotentiation? To the extent that LTP represents the cellular correlate of memory, the processes involved in the depression of synaptic potentiation may contribute to the mechanisms of memory loss ("forgetting"). Considering that stimulation protocols necessary for depotentiation observed in recent studies are common firing patterns observed in endogenous hippocampal theta rhythm during exploration, it is possible that the loss of memory might result from an active process triggered by physiological patterns associated with particular behavioral circumstance. In agreement with this idea, behavioral studies on the stages underlying memory formation have shown that various manipulations can disrupt the encoding of information if applied shortly after initial learning, thereby causing retrograde amnesia (McGaugh et al., 1993; Xu et al., 1998). Thus, besides passive decay and interference forgetting processes, the brain has an active reversal or forgetting process that it uses to erase information selectively and refine memories by removing potentiation in subpopulations of recently stimu- 
lated synapses, thereby preventing saturation of the storage capacity of the neural networks (Stäubli and Chun, 1996).

\section{REFERENCES}

Amaral DG, Witter MP (1989) The three-dimensional organization of the hippocampal formation: a review of anatomical data. Neuroscience 31:571-591.

Anwyl R (1999) Metabotropic glutamate receptors: electrophysiological properties and role in plasticity. Brain Res Rev 29:83-120.

Arai A, Kessler M, Lynch G (1990a) The effects of adenosine on the development of long-term potentiation. Neurosci Lett 119:41-44.

Arai A, Larson J, Lynch G (1990b) Anoxia reveals a vulnerable period in the development of long-term potentiation. Brain Res 511:353-357.

Barrionuevo G, Schottler F, Lynch G (1980) The effects of repetitive low frequency stimulation on control and "potentiated" responses in the hippocampus. Life Sci 27:2385-2391.

Bashir ZI, Collingridge GL (1992) NMDA receptor-dependent transient homo- and heterosynaptic depression in picrotoxin-treated hippocampal slices. Eur J Neurosci 4:485-490.

Bashir ZI, Collingridge GL (1994) An investigation of depotentiation of long-term potentiation in the CA1 region of the hippocampus. Exp Brain Res 100:437-443.

Bear MF, Malenka RC (1994) Synaptic plasticity: LTP and LTD. Curr Opin Neurobiol 4:389-399.

Bienenstock EL, Cooper LN, Munro PW (1982) Theory for the development of neuron selectivity: orientation specificity and binocular interaction in visual cortex. J Neurosci 2:32-48.

Bliss TVP, Collingridge GL (1993) A synaptic model of memory: longterm potentiation in the hippocampus. Nature 361:31-39.

Castillo PE, Weisskopf MG, Nicoll RA (1994) The role of $\mathrm{Ca}^{2+}$ channels in hippocampal mossy fiber synaptic transmission and long-term potentiation. Neuron 12:261-269.

Castillo PE, Janz R, Südhof TC, Malenka RC, Nicoll RA (1997) The synaptic vesicle protein rab3A is essential for mossy fiber long-term potentiation in the hippocampus. Nature 388:590-593.

Conquet F, Bashir ZI, Davies CH, Daniel H, Ferraguti F, Bordi F, Franz-Bacon K, Reggiani A, Matarese V, Condé F, Collingridge GL, Crépel F (1994) Motor deficit and impairment of synaptic plasticity in mice lacking mGluR1. Nature 372:237-243.

Derrick BE, Martinez JLJ (1996) Associative, bidirectional modifications at the hippocampal mossy fiber-CA3 synapse. Nature 381:429-434.

Doherty AJ, Palmer MJ, Bortolotto ZA, Hargreaves A, Kingston AE, Ornstein PL, Schoepp DD, Lodge D, Collingridge GL (2000) A novel, competitive $\mathrm{mGlu}_{5}$ receptor antagonist (LY344545) blocks DHPGinduced potentiation of NMDA responses but not the induction of LTP in rat hippocampal slices. Br J Pharmacol 131:239-244.

Domenici MR, Berretta N, Cherubini E (1998) Two distinct forms of long-term depression coexist at the mossy fiber-CA3 synapse in the hippocampus during development. Proc Natl Acad Sci USA 95:8310-8315.

Dudek SM, Bear MF (1993) Bidirectional long-term modification of synaptic effectiveness in the adult and immature hippocampus. J Neurosci 13:2910-2918

Fujii S, Saito K, Miyakawa H, Ito K, Kato H (1991) Reversal of longterm potentiation (depotentiation) induced by tetanus stimulation of the input to CA1 neurons of guinea pig hippocampal slices. Brain Res 555:112-122.

Gomeza J, Mary S, Brabet I, Parmentier ML, Restituito S, Bockaert J, Pin JP (1996) Coupling of metabotropic glutamate receptors 2 and 4 to $\mathrm{G} \alpha 15, \mathrm{G} \alpha 16$, and chimeric $\mathrm{G} \alpha \mathrm{q} / \mathrm{I}$ proteins: characterization of new antagonists. Mol Pharmacol 50:923-930.

Harris EW, Cotman CW (1986) Long-term potentiation of guinea pig mossy fiber responses is not blocked by $N$-methyl-D-aspartate antagonists. Neurosci Lett 70:132-137.

Henze DA, Urban NN, Barrionuevo G (2000) The multifarious hippocampal mossy fiber pathway: a review. Neuroscience 98:407-427.

Higashima M, Yamamoto C (1985) Two components of long-term potentiation in mossy fiber induced excitation in hippocampus. Exp Neurol 90:529-539.

Hsia AY, Salin PA, Castillo PE, Aiba A, Abeliovich A, Tonegawa S, Nicoll RA (1995) Evidence against a role for metabotropic glutamate receptors in mossy fiber LTP: the use of mutant mice and pharmacological antagonists. Neuropharmacology 34:1567-1572.

Hsu KS (1996) Characterization of dopamine receptors mediating inhibition of excitatory synaptic transmission in the rat hippocampal slice. J Neurophysiol 76:1887-1895.

Huang CC, Hsu KS (1999) Protein tyrosine kinase is required for the induction of long-term potentiation in the rat hippocampus. J Physiol (Lond) 520:783-796.

Huang CC, Hsu KS (2001) Progress in understanding the factors regulating the reversibility in long-term potentiation. Rev Neurosci $12: 51-68$
Huang CC, Liang YC, Hsu KS (1999) A role for extracellular adenosine in time-dependent reversal of long-term potentiation by low-frequency stimulation at hippocampal CA1 synapses. J Neurosci 15:9728-9738.

Ito I, Sugiyama H (1991) Roles of glutamate receptors in long-term potentiation at hippocampal mossy fiber synapses. NeuroReport 2:333-336.

Katsuki H, Kaneko S, Tajima A, Satoh M (1991) Separate mechanisms of long-term potentiation in two input systems to CA3 pyramidal neurons of rat hippocampal slices as revealed by the whole-cell patchclamp technique. Neurosci Res 12:393-402.

Kemp JA, Foster AC, Leeson PD, Priestley T, Tridgett R, Iversen LL, Woodruff GN (1988) 7-Chlorokynurenic acid is a selective antagonist at the glycine modulatory site of the $N$-methyl-D-aspartate receptor complex. Proc Natl Acad Sci USA 85:6547-6550.

Kobayashi K, Manabe T, Takahashi T (1996) Presynaptic long-term depression at the hippocampal mossy fiber-CA3 synapses. Science 273:648-650

Kulla A, Reymann KG, Manahan-Vaughan D (1999) Time-dependent induction of depotentiation in the dentate gyrus of freely moving rats: involvement of group 2 metabotropic glutamate receptors. Eur J Neurosci 11:3864-3872.

Lonart G, Janz R, Johnson KM, Südhof TC (1998) Mechanism of action of rab3A in mossy fiber LTP. Neuron 21:1141-1150.

McGaugh JL, Introini-Collison IB, Cahill LF, Castellano C, Dalmaz C, Parent MB, Williams CL (1993) Neuromodulatory systems and memory storage: role of the amygdala. Behav Brain Res 58:81-90.

Mulkey RM, Herron CE, Malenka RC (1993) An essential role for protein phosphatases in hippocampal long-term depression. Science 261:1051-1055.

Nicoll RA, Malenka RC (1995) Contrasting properties of two forms of long-term potentiation in the hippocampus. Nature 377:115-118.

O'Dell T, Kandel E (1994) Low-frequency stimulation erases LTP through an NMDA receptor-mediated activation of protein phosphatases. Learn Mem 1:129-139.

Pin JP, Duvoisin R (1995) Neurotransmitter receptors. I. The metabotropic glutamate receptors: structure and functions. Neuropharmacology $34: 1-26$

Salin PA, Scanziani M, Malenka RC, Nicoll RA (1996) Distinct shortterm plasticity at two excitatory synapses in the hippocampus. Proc Natl Acad Sci USA 93:13304-13309.

Sejnowksi TJ (1977) Strong covariance with nonlinearly interacting neurons. J Math Biol 4:303-321.

Selig DK, Lee HK, Bear MF, Malenka RC (1995) Reexamination of the effects of MCPG on hippocampal LTP, LTD, and depotentiation. J Neurophysiol 74:1075-1082.

Stäubli U, Chun D (1996) Factors regulating the reversibility of longterm potentiation. J Neurosci 16:853-860.

Stäubli U, Lynch G (1990) Stable depression of potentiated synaptic responses in the hippocampus with $1-5 \mathrm{~Hz}$ stimulation. Brain Res $513: 113-118$

Son H, Carpenter DO (1996) Interactions among paired-pulse facilitation and post-tetanic and long-term potentiation in the mossy fiber-CA3 pathway in rat hippocampus. Synapse 23:302-311.

Tanabe Y, Masu M, Ishii T, Shigemoto R, Nakanishi S (1992) A family of metabotropic glutamate receptors. Neuron 8:169-179.

Tzounopoulos T, Janz R, Südhof TC, Nicoll RA, Malenka RC (1998) A role for cAMP in long-term depression at hippocampal mossy fiber synapses. Neuron 21:837-845.

Vogt KE, Nicoll RA (1999) Glutamate and gamma-aminobutyric acid mediate a heterosynaptic depression at mossy fiber synapses in the hippocampus. Proc Natl Acad Sci USA 96:1118-1122.

Watkins JC, Krogsgaard-Larsen P, Honore I (1990) Structure-activity relationships in the development of excitatory amino acid receptor agonists and competitive antagonists. Trends Pharmacol Sci 11:25-33.

Weisskopf MG, Nicoll RA (1995) Presynaptic changes during mossy fiber LTP revealed by NMDA receptor-mediated synaptic responses. Nature 376:256-259.

Wilshaw D, Dayan P (1990) Optimal plasticity from matrix memories: What goes up must come down. Neural Comput 2:85-93.

Xu L, Anwyl R, Rowan MJ (1998) Spatial exploration induces a persistent reversal of long-term potentiation in rat hippocampus. Nature 394:891-894.

Yokoi M, Kobayashi K, Manabe T, Takahashi T, Sakaguchi I, Katsuura G, Shigemoto R, Ohishi H, Nomura S, Nakamura K, Nakao K, Katsuki M, Nakanishi S (1996) Impairment of hippocampal mossy fiber LTD in mice lacking mGluR2. Science 273:645-647.

Zalutsky RA, Nicoll RA (1990) Comparison of two forms of long-term potentiation in single hippocampal neurons. Science 248:1619-1624.

Zalutsky RA, Nicoll RA (1992) Mossy fiber long-term potentiation shows specificity but no apparent cooperativity. Neurosci Lett 138:193-197.

Zucker RS (1989) Short-term synaptic plasticity. Annu Rev Neurosci 12:13-31. 